\title{
Avaliando o Curso de Ciências Contábeis: uma visão dos alunos da UnB
}

Polyana Barcelos de Paiva"

Fátima de Souza Freire"

José Lúcio Tozetti Fernandes"

\section{Resumo}

O Exame Nacional de Desempenho de Estudantes (Enade) e as avaliações in loco do Ministério da Educação possibilitam a produção de indicadores de qualidade. Com base nos mecanismos de avaliação disponíveis pelos órgãos avaliadores, questiona-se: qual conceito os alunos de Ciências Contábeis da Universidade de Brasilia (UnB) dariam ao seu curso? 0 objetivo do trabalho é identificar pontos fortes e fracos do curso, permitindo que um olhar interno, de seus alunos iniciantes e concluintes, seja instrumento de autorreflexão e compreensão da realidade em busca de aperfeiçoamento e melhora da qualidade da educação. Foi feita uma adaptação do questionário (Reconhecimento de Cursos de Graduação de Bacharelado e Licenciatura) da avaliação dos cursos de graduação do Instituto Nacional de Estudos e Pesquisas Educacionais Anísio Teixeira (Inep) e aplicado aos alunos de Ciências Contábeis da UnB que fizeram a prova do Enade em 2009. Conclui-se que, enquanto as qualificações do coordenador e do corpo docente são os principais pontos fortes, o laboratório especializado, o programa de atendimento extraclasse, o estágio supervisionado e a assinatura de periódicos são os principais gargalos do curso. De uma nota entre 1 a 5, o conceito geral dado ao Curso de Ciências Contábeis pelos seus alunos ficou igual a 3, significando suficiente; vale ressaltar que os iniciantes atribuíram notas mais altas que os concluintes.

Palavras-chave: Avaliação. Enade. Ciências Contábeis.

\section{Evaluating the Accounting Sciences Course: a perspective from UnB students Abstract}

The National Examination of Students Performance (Enade/NESP) and the on-site evaluations of the Ministry of Education allows for the production of quality

Bacharel em Ciências Contábeis; Técnica Judiciária do Superior Tribunal de Justiça. E-mail: polypaiva@hotmail.com

. Doutora em Economia, Université des Sciences Sociales, Toulouse I, França; Professora da Universidade de Brasília (UnB). E-mail: ffreire@unb.br

... Mestre em Contabilidade, UnB; Professor, UnB. E-mail: luciotozetti@unb.br 
indicators. Based on the assessment mechanisms made available by the appraisal organizations, we question: what assessment grade the students in Accounting Sciences from the University of Brasilia (UnB) would give to their course? The objective is to identify the strengths and weaknesses of the course, allowing an inside look from the course's freshmen students and senior undergraduates, also working as a self-reflection and understanding of the reality in search of refinement and improvement of education quality. An adaptation of the questionnaire used for the evaluation of graduation courses by the National Institute of Educational Studies and Research Teixeira (Inep) (Recognition of Undergraduate Courses and Bachelor Degree) was produced and thus applied to students of the Accounting Sciences course of UNB who made the Enade test in 2009. We conclude that while the qualifications of the coordinator and faculty are key strengths of the course, the specialized laboratory, the extra-care program, the supervised training and subscriptions to periodicals are the main hindrances of the course. From the range of possible scores - between 1 and 5 -, the students general assessment grade of the Accounting Sciences Course was equal to 3, meaning sufficient; it should be mentioned that freshmen attributed higher scores than senior undergraduates.

Keywords: Evaluation. ENADE. Accounting.

\section{Evaluación del Curso de Ciencias Contables: una visión de los estudiantes de la UnB (Universidad de Brasilia - Brasil) \\ Resumen}

El Examen Nacional de Desempeño de Estudiantes en Brasil (ENADE) y las evaluaciones in loco del Ministerio de Educación permiten la producción de indicadores de calidad. Con base en los mecanismos de evaluación de las instituciones responsables, surge la pregunta: ¿qué concepto los estudiantes de Ciencias Contables de la Universidad de Brasilia (UnB) le darían a su curso? El objetivo de este trabajo es identificar los puntos fuertes y débiles del curso, permitiendo que una mirada interna, de sus estudiantes iniciantes y de los avanzados en la carrera, sea un instrumento de autorreflexión y comprensión de la realidad en búsqueda de perfeccionamiento y mejora de la calidad de la educación. Se realizó una adaptación del cuestionario (Reconocimiento de Cursos de Graduación Básica y de Licenciatura) usado en la evaluación de los cursos de Graduación Básica del Instituto Nacional de Estudios e Investigaciones Educacionales Anísio Teixeira (INEP). Dicha adaptación se ha aplicado a los estudiantes de Ciencias Contables de la UnB que hicieron el examen del ENADE en 2009. Se concluye que, por un lado, las calificaciones del coordinador y de los profesores son los principales puntos fuertes, pero, por otro, el laboratorio especializado, el programa de atención extra-clase, la pasantía supervisada y las 
suscripciones a publicaciones periódicas son las principales debilidades del curso. En una escala de 1 a 5, los alumnos evaluaron el curso de Ciencias Contables en el grado 03, lo que equivale a suficiente. De este conjunto de estudiantes, los iniciantes atribuyeron notas más altas que los de final de carrera.

Palabras clave: Evaluación. ENADE. Ciencias Contables

\section{Introdução}

No processo avaliativo da educação segundo a lógica da economia de mercado, as maiores ênfases estão voltadas para as análises quantitativas de dados do que para a análise qualitativa, porque os objetivos estão focados para a produtividade, eficiência e controle legal-burocrático das instituições (SCHLICKMANN; MELO; ALPERSTEDT, 2008).

Neste sentido, a avaliação de Instituições de Ensino Superior (IES), embora seja um tema complexo, serve de instrumento de gestão, de desenvolvimento e de tomada de decisão, além de funcionar como base para questões de financiamento junto a órgãos de fomento a pesquisa no país (MARINHO; FAÇANHA, 1999). Citase, por exemplo, a Coordenação de Aperfeiçoamento do Pessoal de Nivel Superior (Capes), que utiliza critérios de avaliação para aprovar projetos de pesquisas e funcionamento de cursos de pós-graduação.

No Brasil, a avaliação das IES é realizada pelo Sistema Nacional de Avaliação da Educação Superior (Sinaes), instituído pela Lei no 10.861 (BRASIL, 2004). Esse sistema promove também a avaliação dos cursos de graduação e a avaliação do desempenho dos estudantes.

Os processos avaliativos do Sinaes são coordenados e supervisionados pela Comissão Nacional de Avaliação da Educação Superior (Conaes) e a operacionalização é de responsabilidade do Instituto Nacional de Estudos e Pesquisas Educacionais Anísio Teixeira (Inep). A avaliação dos cursos de graduação é feita por instrumentos que subsidiam a produção de indicadores de qualidade, e os processos de avaliação são o Enade e as avaliações in loco realizadas pelas comissões de especialistas. 0 Enade avalia o desempenho dos alunos de graduação ingressantes e concluintes em relação aos conteúdos programáticos que estão nas diretrizes curriculares do curso de graduação (SINAES, 2004, p. 137-138).

Considera-se como ingressante qualquer estudante que, até o dia $1^{\circ}$ de agosto de 2009 , tiver cumprido entre $7 \%$ e $22 \%$ da grade curricular mínima do curso, independentemente do período letivo que estiver cursando. E como concluinte qualquer estudante que, até o dia $1^{\circ}$ de agosto de 2009, tiver cumprido pelo menos $80 \%$ da grade curricular mínima do curso, independentemente do período letivo que estiver cursando e o aluno que possa concluir o curso durante 0 ano letivo de 2009, conforme Portaria Normativa n. 1 (BRASIL, 2009a), do Ministério da Educação (MEC). 
A Lei $n^{0} 10.861$ (BRASIL, 2004, Art. $4^{\circ}$, retrata as avaliações in loco dos cursos de graduação, realizadas pelas comissões de especialistas:

A avaliação dos cursos de graduação tem por objetivo identificar as condições de ensino oferecidas aos estudantes, em especial as relativas ao perfil do corpo docente, às instalações físicas e à organização didático-pedagógica.

$\S 1^{\circ} \mathrm{A}$ avaliação dos cursos de graduação utilizará procedimentos e instrumentos diversificados, dentre os quais obrigatoriamente as visitas por comissões de especialistas das respectivas áreas do conhecimento.

$\S 2^{\circ} \mathrm{A}$ avaliação dos cursos de graduação resultará na atribuição de conceitos, ordenados em uma escala com 5 (cinco) níveis, a cada uma das dimensões e ao conjunto das dimensões avaliadas.

0 desempenho de um estudante pode ser determinado por diversos fatores. Hanushek e Luque (2001 apud SOUZA, 2008, f. 15) dividem esses fatores em escolares e não escolares. Os fatores não escolares estariam relacionados a questões sociodemográficos e comportamentais. E os fatores escolares, aos recursos da instituição de ensino, tais como: infraestrutura, experiências profissionais e competências científico-pedagógicas do corpo docente.

Os fatores escolares são avaliados pelas comissões de especialistas quando da realização de avaliações in loco, ao responderem questionário oferecido pelo Inep, que vem estruturado em três dimensões: organização didático-pedagógica, corpo docente e instalações físicas. As dimensões se dividem em indicadores, que representam algum aspecto da realidade a ser avaliada.

Schlickmann, Melo e Alperstedt (2008) apresentam quatro critérios quanto às concepções de avaliação e de comparabilidade entre as instituições, a saber: ideológicos (educação como bem público e educação segundo a lógica do mercado), objetivos (produção do conhecimento), participativos dos indivíduos na avaliação (caráter heurístico e qualitativo) e complexidade (imprevisivel e incomensurável). Neste contexto, para subsidiar uma interferência na forma organizada dos serviços prestados a sociedade, os indivíduos (alunos, professores e funcionários) no processo avaliativo "são os que têm mais autoridade intelectual e profissional para avaliar as atividades e os resultados das práticas educacionais" (DIAS SOBRINHO, 2005 apud SCHLICKMANN; MELO; ALPERSTEDT, 2008, p. 158).

Os alunos do Curso de Ciências Contábeis da Universidade de Brasília (UnB) realizaram o Enade de 2006 (INEP, 2006b), quando recebeu conceito máximo, e recentemente passou pelo Enade 2009, porém o curso não teve ainda as avaliações in loco pelas comissões especializadas. 
Em função da ênfase dada pelo Sinaes (INEP, 2004), bem como da importância que tem sido referendada por teóricos (DIAS SOBRINHO, 2000; STEIN, 2001) à avaliação das IES como instrumento para subsidiar a melhoria da qualidade da educação no país, motivou-se a realização de um estudo sobre a percepção dos indivíduos (alunos) do curso de Ciências Contábeis quanto à gestão acadêmica de sua universidade. Isto decorre da finalidade de responder a seguinte questão: Como o Curso de Ciências Contábeis da UnB seria avaliado por seus alunos numa avaliação in loco?

0 objetivo do trabalho é verificar quais são os pontos fortes e fracos, segundo a opinião dos alunos, quanto à organização didático-pedagógica, corpo docente e instalações físicas do Curso de Ciências Contábeis da UnB. Tem ainda como objetivo específico comparar a opinião e nota dada pelos alunos iniciantes e concluintes (parâmetro utilizado pelo MEC).

Para a realização do estudo, foi aplicado um questionário, adaptado do "Reconhecimento de Cursos de Graduação de Bacharelado e Licenciatura" da avaliação dos cursos de graduação do Inep, aos alunos do Curso de Ciências Contábeis da UnB, no segundo semestre de 2009. Para chegar ao conceito final da avaliação, fezse uma análise quantitativa das dimensões, destacando os indicadores máximos e mínimos de cada dimensão. Fez-se, também, uma análise diferenciada dos alunos ingressantes e concluintes. A aplicação do questionário foi feita, em sala de aula, aos alunos que cursavam as matérias do primeiro e do último ano do Curso de Ciências Contábeis da UnB, diurno e noturno, no mês de novembro de 2009.

Contando com esta introdução, o trabalho está dividido em cinco seções. A seção 2 referencia a parte teórica, que define avaliação e apresenta objetivos e justificativas do porquê avaliar. A seção 3 apresenta a metodologia e os dados utilizados na pesquisa, que se deu pela utilização de estatística descritiva e uma análise quantitativa dos conceitos atribuídos pelos alunos selecionados para fazer a prova do Enade 2009 do Curso de Ciências Contábeis. A seção 4 analisa os resultados obtidos, apresentando a amostra utilizada, e identifica os conceitos máximos e mínimos, bem como a média de cada dimensão e a média ponderada final geral, dos iniciantes e dos concluintes. Por fim, a seção 5, apresenta as conclusões e perspectivas para a realização de novos estudos voltados para avaliação de IES.

\section{Referencial teórico}

Segundo Bueno (1996) avaliar é estimar, aquilatar, aferir, apreciar; e o Inep (2006a, p. 32) traz ainda que "Etimologicamente, avaliar significa atribuir valor a alguma coisa, dar a valia [...]".

0 ser humano está sempre avaliando, como bem colocado por Schmitz (2008, p. 23), é provável que o homem avalie desde a sua existência, pois a usa para fazer 
escolhas, tomar decisões, atribuir valores, aperfeiçoar-se, podendo ser usado para diversas finalidades, áreas e entidades. Dias Sobrinho (2003) diz que as avaliações são antigas e surgiram com o objetivo de qualificar e principalmente selecionar funcionários de órgãos públicos. A China fazia avaliações para seleção de servidores e a Grécia verificava as aptidões morais dos candidatos (SCHMITZ, 2008, p. 16).

Têm-se apresentado várias justificativas para a avaliação das instituições superiores. Dias Sobrinho (2000, p. 67) traz dois pontos: o imperativo ético de transparência em relação à sociedade, e a ideia de que a avaliação é um importante mecanismo de luta política pela salvaguarda da universidade pública, constantemente ameaçada pelas ideias privatizantes e por concepções utilitaristas. 0 governo traz no sítio do Inep que a avaliação está relacionada à melhoria da qualidade da educação superior, à orientação da expansão de sua oferta, e ao aumento permanente da sua eficácia institucional e efetividade acadêmica. Stein (2001, p. 30) traz ainda seis concepções de avaliação: avaliação para tomada de decisão e para o aperfeiçoamento, avaliação de mérito, avaliação iluminativa (compreensão da realidade), avaliação responsiva (com fins de prestação de contas), avaliação emancipatória e avaliação como forma de pesquisa avaliativa.

Na publicação do "Sinaes: da concepção à regulamentação' (INEP, 2004, p. 97), surgem ainda alguns objetivos da avaliação:

Entre os objetivos da avaliação contam-se o de conhecer as fortalezas e os problemas da instituição, tratar da adequação de seu trabalho com respeito às demandas sociais, as clássicas e as novas, identificar os graus de envolvimento e os compromissos de seus professores, estudantes e servidores tendo em vista as prioridades institucionais básicas.

No Brasil, a avaliação do Ensino Superior começou a ter destaque na década de setenta, no regime militar, priorizado por muitos autores como marco inicial, uma vez que foi nesse periodo que se processou a reforma universitária.

Segundo Cunha (1989 apud REAL, 2008, p. 32) "os impactos da reforma de 1968 foram determinantes para a construção da concepção de qualidade pretendida nos anos de 1980, que seria viabilizada pela consolidação da universidade como espaço privilegiado de formação". Real (2008, p. 32), citando Schwartzman (1990), traz ainda que este informa, ao descrever o contexto institucional e político em que surge a avaliação do ensino superior, que "a reforma de 1968 teve um efeito paradoxal, cujas consequências ainda são sentidas de forma extremamente forte".

Após 1995, segundo Real (2008, p. 46), começa a ser feita a avaliação no ensino superior em grande escala. 
Todo o processo de avaliação, interna ou externa, age de forma dinâmica e integrada, em diálogo, dando subsídios para o aprimoramento dos processos institucionais que buscam a qualidade. Para o MEC a avaliação integrada deve ser interna e externa, possibilitando a auto-reflexão que deva considerar também aspectos qualitativos. Sendo assim, a avaliação externa tem como fonte de informação o processo de avaliação interna e de auto-avaliação da IES (INEP, 2006a, p. 33).

Dias Sobrinho (2000, p. 128) comenta também sobre a interação das avaliações interna e externa, sendo os sujeitos na primeira, pertencentes à mesma realidade que está sendo avaliada e, quando se dá por autoavaliação, são também parte do objeto, tendo por finalidade a ampliação de conhecimentos e valoração do objeto de análise. Já a externa confirma o sentido de transparência e o caráter público da universidade e da avaliação, pela participação efetiva dos membros da comunidade científica, de órgãos públicos e de representantes da sociedade organizada.

No que diz respeito à avaliação de instituições de ensino superior, cita-se estudos de Freire, Crisóstomo e Castro (2007), que verificaram se o desempenho administrativo das Instituições Federais de Ensino Superior (IFES), medido por um conjunto de indicadores de gestão, tem relação com o desempenho acadêmico. Realizou-se uma pesquisa numa amostra de 27 Ifes no ano de 2005. Constataram-se que os resultados obtidos mostraram um reflexo positivo de indicadores relacionados com o interesse discente em sua própria formação, medida pela taxa de sucesso e maior dedicação ao curso. Na mesma direção, se encontrou um efeito favorável da relação entre número de alunos e funcionários. Entretanto, não se detectou um esperado efeito positivo do custo por aluno no desempenho deste.

Souza e outros (2009) aplicou a teoria das restrições (TOC) na gestão de uma IES com o objetivo de verificar quais foram as disciplinas que causavam as maiores restrições no fluxo de estudos dos alunos de contabilidade. Verificou-se que a disciplina Contabilidade Comercial se apresentou como alta restrição tanto pela análise do índice de reprovação quanto pela análise do desempenho do professor. Os resultados poderão auxiliar os coordenadores de Curso e Chefes de Departamento a tomarem iniciativas quanto ao estabelecimento de políticas que diminuam as restrições, como por exemplo, a criação de monitorias, grupos de estudos e orientações pedagógicas. Enquanto isso, Aligleri e Macrini (2004), tomando-se por base uma IES do Paraná como estudo de caso, concluíram que a TOC, em sua lógica, como uma forma de descoberta democrática, se apresenta bastante útil como um método claro na solução de problemas e decisões organizacionais no ensino superior. Vale inferir que a TOC (GOLDRAT, 1993) auxilia na construção de procedimentos lógicos, no uso de ideias estruturadas, através de análises baseadas em relações de causa e efeito. Sinaliza-se que estas são condições necessárias para encontrar soluções simples e práticas em conflitos. Goldratt (1993), emprega a lógica da indução de erros a partir da teoria de sistemas como forma de aprendizado para o estabelecimento da meta global da entidade. 
Woylnec (1992) defende a ideia de que, na avaliação das universidades públicas do país, é importante a definição de um conjunto de indicadores que permita a comparação entre instituições.

Nesse sentido, por observar a importância que a avaliação pode trazer para os gestores de IES, justifica-se a realização do estudo na avaliação, na percepção e na visão do aluno do seu curso quanto às condições de oferta dos serviços, servindo como base para a tomada de decisão interna.

\section{Procedimentos da pesquisa}

0 universo de alunos iniciantes e concludentes do presente trabalho foi aquele já selecionado e escolhido de forma aleatória pelo MEC para fazerem a prova do Enade 2009, considerados aptos a representarem a IES na avaliação. A relação dos alunos foi divulgada no departamento do curso, perfazendo um total de 238 estudantes do curso diurno e noturno de Ciências Contábeis. A enquete ocorreu no mês de novembro de 2009, nas turmas de Contabilidade Geral 2, Contabilidade de Companhias Abertas e Laboratório Contábil, diurno e noturno, pertencentes ao $2^{\circ}$ e $8^{\circ}$ semestres do fluxo do curso de Ciências Contábeis e segundo as porcentagens estabelecidas pelo MEC para os estudantes se enquadrarem como alunos iniciantes ou concluintes. Do total de 238 alunos aptos a fazerem o teste, 85 foram selecionados para responderem o questionário, representando um total de $35,71 \%$ da população estudada.

0 questionário foi adaptado a partir do instrumento de avaliação "Reconhecimento de Cursos de Graduação de Bacharelado e Licenciatura", utilizado pelo Inep e aprovado pela Portaria $n^{\circ} .2$ (BRASIL, 2009b).

Os dados da pesquisa foram coletados a partir dos conceitos atribuídos pelos alunos aos indicadores de cada dimensão apresentados no questionário, estruturado da seguinte maneira: apresentação do objeto de pesquisa, perfil do aluno, instruções do questionário, onde se orienta os alunos a atribuírem conceitos de 1 a 5 para cada indicador apresentado, sendo: 1 - não, não há ou não existe; 2 - insuficiente; 3 - suficiente; 4 - plena e 5 - excelente. E uma quarta parte, que são os indicadores a serem avaliados, dividido em três dimensões: Dimensão 1 - Organização Didático-Pedagógica; Dimensão 2 - Corpo Docente e Dimensão 3 - Instalações Físicas. A Dimensão 1 é formada por 13 indicadores, onde os indicadores 1 e 13 foram subdivididos em 3 subitens. A Dimensão 2 é formada por 11 indicadores e a Dimensão 3, por 10 indicadores.

Vale ressaltar que no questionário não foram colocados alguns indicadores presentes no instrumento de avaliação do Inep, por se tratarem de assuntos que não são de conhecimento da maioria dos alunos como, por exemplo, políticas institucionais constantes do plano de desenvolvimento institucional, implementação de ações acadêmico-administrativas e núcleo docente estruturante.

Foi utilizada estatística descritiva, resumindo os dados e descrevendo-os por meio de uma análise quantitativa, tanto na modalidade da coleta da informação, 
quanto do tratamento por meio de técnicas estatísticas, tais como média aritmética, média ponderada, média global de dados combinados, desvio padrão e moda.

0 conceito de média global de dados combinados foi retirado do livro de Freund e Simon (2000, p. 43), que é uma aplicação especial da fórmula da média ponderada quando se necessita achar a média de $k$ conjuntos de dados com médias $x_{1}, x_{2}, x_{3}, \ldots$, $x_{k^{\prime}}$ e consistindo de $n_{1}, n_{2}, n_{3}, \ldots, n_{k}$ medidas ou observações. 0 resultado é:

$$
\text { Média Global de dados combinados }=\frac{n 1 \times 1+n 2 \times 2+n 3 \times 3+\ldots+n k \times k}{n 1+n 2+n 3+\ldots+n k}
$$

onde, os pesos são os tamanhos dos respectivos conjuntos de dados, o numerador é o total de todas as medidas ou observações, e o denominador é o número total de elementos nos dados combinados.

Para calcular os conceitos das dimensões e da nota final foi utilizada a média global de dados combinados, e usado como peso os definidos à cada dimensão juntamente com o número de indicadores da respectiva dimensão. O Sinaes (INEP, 2006a) diz que a definição dos pesos, além de contemplar a participação diferenciada de cada uma das dimensões no processo de construção da qualidade da IES, deve considerar também o número de indicadores presentes nas mesmas. "Desta forma, torna-se possível evitar que a importância relativa de um indicador, na composição do conceito final, seja potencializada ou reduzida em consequência da forma de apropriação dos resultados" (INEP, 2006a, p. 23).

Segundo a Portaria n 2 (BRASIL, 2009b), a nota da avaliação do Reconhecimento de Cursos de Graduação de Bacharelado e Licenciatura é calculada, atribuindo pesos às dimensões 1, 2 e 3, sendo eles 40, 35 e 25, respectivamente.

Assim, o cálculo final da avaliação foi feito pela média ponderada das três dimensões, considerando os pesos da Portaria $n^{\circ} 2$ (BRASIL, 2009b) e do número de indicadores que tem cada dimensão, representado na equação 2.

$$
A v=\frac{40 \times 11 \times D 1+35 \times 12 \times D 2+25 \times 13 \times D 3}{40 \times 11+35 \times 12+25 \times 13}
$$

Onde,

Av = Conceito final da avaliação ou Média Ponderada Final (MPF)

I1 = número de indicadores presentes na Dimensão 1

12 = número de indicadores presentes na Dimensão 2

I3 = número de indicadores presentes na Dimensão 3

D1 = conceito médio da Dimensão 1

D2 = conceito médio da Dimensão 2

D3 = conceito médio da Dimensão 3 
Para se chegar a um conceito de cada dimensão e nota final, foi utilizado o padrão do Sinaes, alterando os intervalos que seriam a critério dos avaliadores, sendo definido segundo a moda da amostra em questão, significando o conceito que aparece mais vezes no indicador ou na dimensão respectiva. As médias que definem cada conceito se encontram esquematizadas no Quadro 1.

Quadro 1 - Correspondência entre a média atribuída aos indicadores e o conceito final.

\begin{tabular}{|c|c|c|}
\hline $\begin{array}{c}\text { Média aritmética dos } \\
\text { indicadores da dimensão } \\
\text { (MAl) }\end{array}$ & $\begin{array}{c}\text { Conceito da dimensão/ } \\
\text { Conceito final }\end{array}$ & $\begin{array}{c}\text { Faixa de valores para } \\
\text { Média Ponderada } \\
\text { Final (MPF) }\end{array}$ \\
\hline $1,0=<\mathrm{MAl}=<1,4$ & 1 & $1,0=<\mathrm{MPF}=<1,4$ \\
\hline $1,4=<\mathrm{MAl}=<1,7$ & 1 ou 2, o que for a moda da amostra & $1,4=<\mathrm{MPF}=<1,7$ \\
\hline $1,7=<\mathrm{MAl}=<2,4$ & 2 & $1,7=<\mathrm{MPF}=<2,4$ \\
\hline $2,4=<\mathrm{MAl}=<2,7$ & 2 ou 3, o que for a moda da amostra & $2,4=<\mathrm{MPF}=<2,7$ \\
\hline $2,7=<\mathrm{MAl}=<3,4$ & 3 & $2,7=<\mathrm{MPF}=<3,4$ \\
\hline $3,4=<\mathrm{MAl}=<3,7$ & 3 ou 4, o que for a moda da amostra & $3,4=<\mathrm{MPF}=<3,7$ \\
\hline $3,7=<\mathrm{MAl}=<4,4$ & 4 & $3,7=<\mathrm{MPF}=<4,4$ \\
\hline $4,4=<\mathrm{MAl}=<4,7$ & 4 ou 5, o que for a moda da amostra & $4,4=<\mathrm{MPF}=<4,7$ \\
\hline $4,7=<\mathrm{MAl}=<5,0$ & 5 & $4,7=<\mathrm{MPF}=<5,0$ \\
\hline
\end{tabular}

Fonte: Adaptado de Inep (2006a, p. 83).

Com a segunda parte do questionário, fez-se um levantamento de dados descritivos do perfil da amostra, o que originou a tabela 1. Foi obtida uma amostra homogênea quanto a distribuição entre homens e mulheres variando, no total de alunos, em apenas 2 pontos percentuais. Quanto à distribuição no fluxo, 58,82\% dos alunos estão na categoria iniciantes, e 41,18\% dos alunos estão na categoria concluintes.

Tabela 1 - Dados descritivos do perfil da amostra.

\begin{tabular}{|c|c|c|c|c|c|c|}
\hline Alunos & $\%$ & Sexo & $\%$ & Semestre & $\%$ & Idade \\
\hline \multirow{2}{*}{$\begin{array}{l}\text { Iniciantes } \\
50 \text { alunos }\end{array}$} & \multirow{2}{*}{$58,82 \%$} & Homens & $42 \%$ & $2^{\circ}$ & $76 \%$ & \multirow{2}{*}{ de 17 a 22 anos } \\
\hline & & Mulheres & $58 \%$ & $3^{\circ}$ & $24 \%$ & \\
\hline \multirow{6}{*}{$\begin{array}{l}\text { Concluintes } \\
35 \text { alunos }\end{array}$} & \multirow{6}{*}{$41,18 \%$} & \multirow{3}{*}{ Homens } & & $6^{\circ}$ & $5,71 \%$ & \multirow{6}{*}{ de 20 a 35 anos } \\
\hline & & & $60 \%$ & $7^{0}$ & $25,71 \%$ & \\
\hline & & & & $8^{\circ}$ & $34,29 \%$ & \\
\hline & & \multirow{3}{*}{ Mulheres } & & $9^{\circ}$ & $20,00 \%$ & \\
\hline & & & $40 \%$ & $10^{\circ}$ & $11,43 \%$ & \\
\hline & & & & $12^{\circ}$ & $2,86 \%$ & \\
\hline \multirow{2}{*}{ Total } & \multirow{2}{*}{85 alunos } & Homens & $49 \%$ & & & \\
\hline & & Mulheres & $51 \%$ & & & \\
\hline
\end{tabular}

Fonte: As autoras (2010). 
Os alunos iniciantes se concentram no $2^{\circ}$ semestre do curso e suas idades variam de 17 a 22 anos, sendo que a maioria, 74\%, tem 18 ou 19 anos. Já os alunos concluintes se concentram no $8^{\circ}$ semestre do curso, mas com quantidades consideráveis nos $7^{\circ}$ e $9^{\circ}$ semestres. A moda das idades dos alunos concluintes é de 21 anos, sendo a média das idades 24 anos, com um desvio padrão de 3,97.

Foram realizados testes de médias dos conceitos atribuidos para cada indicador como forma de averiguar se os alunos ingressantes avaliaram de maneira significativamente diferente os quesitos em relação aos alunos concluintes. Desta forma, o teste trabalha com a hipótese estatística nula de que as amostras possuem igualdade das médias e hipótese estatística alternativa de que as médias das amostras não são iguais.

0 teste de médias com duas formas de consecussão tem como pressuposto a igualdade da variância dos grupos amostrais. Assim, para amostras com variâncias iguais é realizado o teste de médias para duas amostras, presumindo variâncias equivalentes; e, para amostras com variâncias diferentes, é operacionalizado o teste de médias para duas amostras presumindo variâncias diferentes.

Portanto, para identificar se há igualdade nas variâncias dos conceitos dados pelos alunos ingressantes e concluintes, previamente, foi conduzido o Teste de Levene, o qual examina se a variância de dois grupos amostrais não são iguais (hipótese estatística nula) ou se são iguais (hipótese estatística alternativa). Os testes foram calculados utilizando-se o programa estatístico Statistic Package for Social Science (SPSS).

\section{Resultados}

Foi calculado um conceito para cada indicador das dimensões com a média aritmética das notas que cada aluno deu ao respectivo indicador, e para o cálculo do conceito de cada dimensão foi utilizada a média global de dados combinados dos indicadores.

Os conceitos atribuidos a cada indicador estão representados nas Figuras 1 (Organização Didático-Pedagógica), 2 (Corpo Docente) e 3 (Instalações Físicas). Os indicadores e as médias das dimensões estão representados por três barras, sendo a de cor branca referente às notas atribuídas por todos os alunos, as pretas, por alunos iniciantes e as cinzas, por alunos concluintes.

A média geral da Dimensão 1 - Organização Didático-Pedagógica (D1) foi de 3,10 , enquanto o desvio-padrão de 1,02 e desvio-padrão para as médias dos indicadores de 0,41 . Observa-se, também, que a moda para esta dimensão se manteve no conceito 3. Os indicadores com melhores resultados foram 1.2 - Dedicação do coordenador ao curso (3,38), 2 - Experiência do Coordenador (3,91), 3 - Objetivos do curso $(3,48), 4$ - Satisfação do Perfil do Egresso com o Curso $(3,57)$ e 6 Relevância e coerência dos conteúdos curriculares $(3,42)$. 
Por outro lado, os indicadores com menores resultados $(2,35)$ foram 8 - Programas de atendimento extraclasse, de apoio psicopedagógico e atividades de nivelamento ao aluno e 10 - Estágio supervisionado previsto no currículo com locais e supervisão adequados $(2,48)$. É interessante observar que todos os alunos atribuíram algum conceito ao indicador 8 e que $62,35 \%$ dos estudantes acham que não há, ou é insuficiente, os programas de atendimento extraclasse, de apoio psicopedagógico e atividades de nivelamento a eles.

Quando analisado separadamente os conceitos atribuídos pelos iniciantes e os concluintes, observa-se que a nota da D1 ficou igual a 3,27 e 2,89, respectivamente, demonstrando que existe uma menor satisfação dos alunos do final do curso em relação aos ingressantes. Notou-se que, para os concluintes, o indicador da D1 de número 8 - Programas de atendimento extraclasse, de apoio psicopedagógico e atividades de nivelamento ao aluno apresenta conceito baixo, com $71,42 \%$ dos alunos atribuindo conceitos 1 ou 2, mas apresentou outro indicador com nota mínima, o de número 10 - Estágio supervisionado previsto no currículo com locais e supervisão adequados, que para os concluintes passou a ser o indicador de menor conceito, com 2,03, onde 77,14\% dos alunos atribuíram conceitos 1 ou 2, enquanto os iniciantes atribuíram nota média de 2,84 para este indicador. Nos indicadores 13.1 a 13.3 da D1, referentes a trabalho de conclusão de curso, os alunos iniciantes atribuiram conceitos maiores que os alunos concluintes, sendo que aqueles ainda não fizeram o trabalho de conclusão de curso para poderem avaliá-lo.

Os resultados dos testes de médias dos conceitos atribuídos pelos alunos aos indicadores da dimensão 1 são apresentados na tabela 2.0 primeiro teste realizado, para verificar igualdade de variância entre os conceitos atribuidos pelos alunos ingressantes e concluintes, mostra que os conceitos dados aos indicadores 5 e 13.1 não apresentam variâncias iguais entre os dois grupos. Assim, para esses indicadores foi realizado o teste t para igualdade das médias não assumindo variâncias iguais, enquanto que, para os demais indicadores, foram calculadas as estatísticas teste assumindo variância iguais.

A partir das estatísticas testes, verificam-se que as diferenças dos conceitos entre os grupos de alunos iniciantes e concluintes atribuídos aos indicadores 1.3 Diálogo, transparência e liderança no exercício das funções, 4 - A efetiva implementação do curso atende ao perfil do egresso proposto, 5 - Interação entre alunos e professores, 10 - Estágio supervisionado previsto no currículo com locais e supervisão adequados, 11 - Adequação da carga horária das atividades de prática profissional e/ou estágio, 13.1 - Mecanismos efetivos de acompanhamento e de cumprimento das atividades, 13.2 - Meio de divulgação de TCCs, e 13.3 - Tempo disponível do professor na orientação de TCC são estatisticamente significantes, ou seja rejeita-se a hipótese nula. 
Figura 1: Conceitos atribuidos pelos alunos para a dimensão1.

Dimensão 1 - Organização Didático-Pedagógica

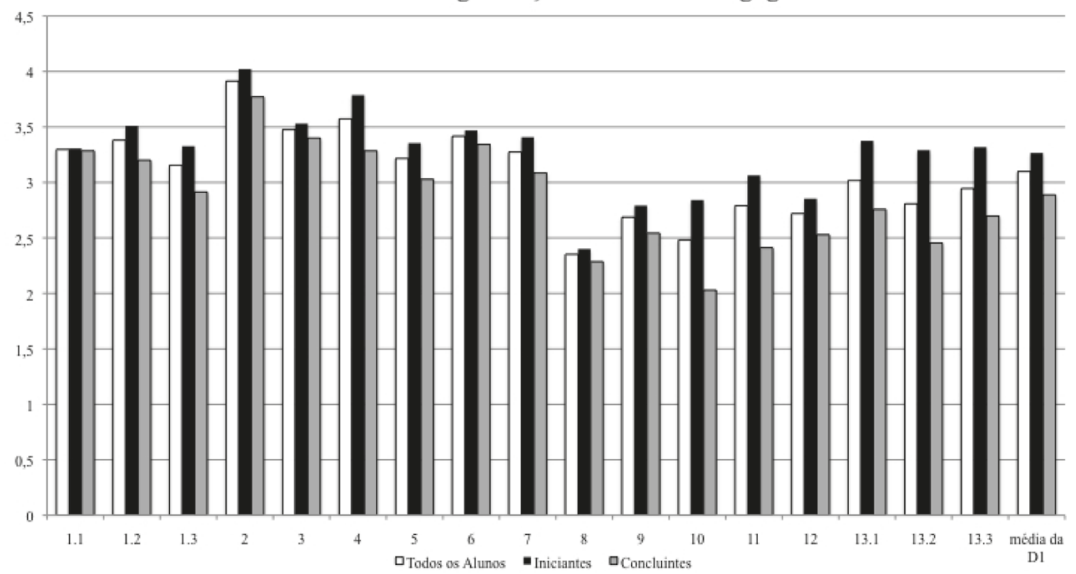

Dimensão 1 - Organização Didático-Pedagógica

1. Atuação do Coordenador.

1.1 Atendimento aos alunos e professores.

1.2 Dedicação à gestão do curso.

1.3 Diálogo, transparência e liderança no exercício das funções.

2. Experiência do Coordenador (acadêmica e profissional).

3. A efetiva implementação do curso atende aos objetivos propostos e expressa os compromissos institucionais em relação ao ensino, à pesquisa e à extensão.

4. A efetiva implementação do curso atende ao perfil do egresso proposto.

5. Interação entre alunos e professores
6. Relevância, atualização e coerência dos conteúdos curriculares com os objetivos do curso. Dimensionamento da carga horária para seu desenvolvimento e complemento de atividades extraclasse definidas e articuladas com o processo global de formação.

7. Metodologia utilizada no desenvolvimento das atividades do curso.

8. Programas de atendimento extraclasse, de apoio psicopedagógico e atividades de nivelamento ao aluno.

9. Estímulos aos alunos para a realização de atividades acadêmicas e eventos externos, com divulgação, preparação e apoio.
10. Estágio supervisionado previsto no currículo com locais e supervisão adequados. 11. Adequação da carga horária das atividades de prática profíssional e/ou estágio.

12. Atividades complementares com temas pertinentes e complementares ao curso.

13. Trabalho de conclusão de curso (TCC)

13.1 Mecanismos efetivos de

acompanhamento e de cumprimento das atividades

13.2 Meios de divulgação de TCCs

13.3 Tempo disponível do professor na orientação de TCC

Fonte: As autoras (2010).

Estes resultados dos testes de médias denotam que há uma diferença significativa dos conceitos atribuídos pelos alunos ingressantes e concluintes para cada um desses indicadores. De fato, os alunos ingressantes avaliaram de maneira mais positiva os indicadores, como pode ser observado na coluna de diferença das médias da tabela 2.

As diferenças de opinião dos indicadores relacionados ao Trabalho de Conclusão de Curso $(13.1,13.2$ e 13.3) devem-se, provavelmente, ao fato de esse trabalho ter sido feito apenas no final do curso. Assim, como os alunos iniciantes não fizeram o TCC, acabaram avaliando melhor esses indicadores que os alunos concluintes.

Os indicadores 10 e 11 obtiveram conceitos significativamente diferentes por estarem, possivelmente, relacionados com a expectativa que os alunos ingressantes têm em relação à adequação do currículo às necessidades profissionais. Uma vez que o currículo não apresenta, na sua grade, como obrigatório o estágio supervisionado e o interesse por ele são mais dos alunos concluintes, estes acabam por atribuir conceitos menores que os atribuidos pelo ingressantes. 
0 que pode estar relacionado, também, com as expectativas que os alunos ingressantes têm em relação ao curso é o indicador 4, que questiona se a efetiva implementação do curso atende ao perfil do egresso proposto pela IES.

Quanto ao indicador 1.3, que se refere ao diálogo, transparência e liderança do coordenador no exercício das funções, a diferença significativa dos conceitos atribuídos, possivelmente, deve-se ao fato de que os alunos ingressantes têm uma reunião com os coordenadores para orientações quanto ao curso e à realização da matrícula nas matérias. Soma-se à diferença significativa de atribuição dos conceitos pelos alunos ingressantes e concluintes, o curso noturno, no ano da presente avaliação, ficar sem coordenador por um período.

A diferença significativa dos conceitos atribuídos ao indicador 5 deve-se, provavelmente, ao desgaste que pode haver ao longo do curso entre alunos e professores; e a probabilidade de desgaste é maior para os alunos concluintes, que tiveram mais tempo com os professores.

Para os outros indicadores da dimensão 1, os testes de médias não rejeitaram a hipótese de igualdade dos conceitos atribuídos pelos alunos ingressantes e concluintes. Logo, pode-se afirmar que os conceitos outorgados a esses indicadores são iguais, sendo que as diferenças encontradas são devidas meramente ao acaso. $\mathrm{Ou}$ seja, os alunos ingressantes e concluintes avaliaram praticamente da mesma forma os indicadores $1.1 ; 1.2 ; 2 ; 3 ; 6 ; 7 ; 8 ; 9$ e 12 . 
Tabela 2 - Resultados dos testes de médias dos indicadores da dimensão 1.

\begin{tabular}{l|c|c|c|c|c}
\hline Indicadores & \multicolumn{2}{|c|}{ Resultado teste de Levene } & \multicolumn{3}{|c}{ Teste t para igualdade das médias } \\
\hline & Estatistica F & Significância & Estatística t & Significância & Diferença das médias \\
\hline 1.1 & 2,251 & 0,137 & $0,105^{*}$ & 0,917 & 0,020 \\
\hline 1.2 & 0,923 & 0,340 & $1,798^{*}$ & 0,076 & 0,310 \\
\hline 1.3 & 0,502 & 0,481 & $2,306^{*}$ & 0,024 & 0,412 \\
\hline 3 & 0,002 & 0,968 & $1,134^{*}$ & 0,260 & 0,251 \\
\hline 4 & 1,103 & 0,297 & $0,588^{*}$ & 0,558 & 0,131 \\
\hline 5 & 0,195 & 0,660 & $2,572^{*}$ & 0,012 & 0,502 \\
\hline 7 & 4,204 & 0,044 & $2,042^{* *}$ & 0,044 & 0,326 \\
\hline 8 & 0,018 & 0,894 & $0,627^{*}$ & 0,532 & 0,127 \\
\hline 9 & 0,271 & 0,604 & $1,724^{*}$ & 0,089 & 0,322 \\
\hline 10 & 0,834 & 0,364 & $0,538^{*}$ & 0,592 & 0,114 \\
\hline 11 & 1,671 & 0,200 & $1,234^{*}$ & 0,221 & 0,249 \\
\hline 12 & 1,031 & 0,313 & $3,970^{*}$ & 0,000 & 0,812 \\
\hline 13.1 & 0,963 & 0,330 & $2,860^{*}$ & 0,005 & 0,652 \\
\hline 13.3 & 2,599 & 0,111 & $1,394^{*}$ & 0,167 & 0,325 \\
\hline$F 0 n t: A s$ & 3,945 & 0,052 & $2,383^{* *}$ & 0,022 & 0,617 \\
\hline 1,564 & 0,216 & $3,236^{*}$ & 0,002 & 0,837 \\
\hline
\end{tabular}

Fonte: As autoras (2010).

Legenda dos indicadores: (1) Atuação do Coordenador; (1.1) Atendimento aos alunos e professores; (1.2) Dedicação à gestão do curso; (1.3) Diálogo, transparência e liderança no exercício das funções; (2) Experiência do Coordenador (acadêmica e profissional); (3) A efetiva implementação do curso atende aos objetivos propostos e expressa os compromissos institucionais em relação ao ensino, à pesquisa e à extensão; (4) A efetiva implementação do curso atende ao perfil do egresso proposto; (5) Interação entre alunos e professores; (6) Relevância, atualização e coerência dos conteúdos curriculares com os objetivos do curso. Dimensionamento da carga horária para seu desenvolvimento e complemento de atividades extraclasse definidas e articuladas com o processo global de formação; (7) Metodologia utilizada no desenvolvimento das atividades do curso; (8) Programas de atendimento extraclasse, de apoio psicopedagógico e atividades de nivelamento ao aluno; (9) Estímulos aos alunos para a realização de atividades acadêmicas e eventos externos, com divulgação, preparação e apoio; (10) Estágio supervisionado previsto no currículo com locais e supervisão adequados; (11) Adequação da carga horária das atividades de prática profissional e/ou estágio; (12) Atividades complementares com temas pertinentes e complementares ao curso; (13) Trabalho de conclusão de curso (TCC); (13.1) Mecanismos efetivos de acompanhamento e de cumprimento das atividades; (13.2) Meios de divulgação de TCCs; (13.3) Tempo disponivel do professor na orientação de TCC.(*) Assumindo variâncias iguais; $\left.{ }^{* *}\right)$ Não assumindo variâncias iguais.

A Dimensão 2 - Corpo Docente (D2) ficou com a maior nota média das três dimensões, 3,40, cujo desvio-padrão da amostra D2 é de 0,98, e o desvio-padrão dos indicadores é de 0,31. 0 indicador que obteve maior nota foi o de número 1 - Formação do coordenador do curso, com 3,75; e o que obteve menor nota foi o indicador de número 11 - 
Desenvolvimento de pesquisa, com participação de estudantes (iniciação científica) e número de produção por docente, com 2,59. Este indicador foi o único de sua dimensão que ficou com nota menor que 3, onde mais de 50\% dos alunos atribuíram conceitos 1 ou 2 .

Vale frisar que os alunos concluintes atribuíram, no geral, conceitos maiores que os iniciantes, mas muito próximos na dimensão 2 . Para os concluintes o conceito médio da D2 foi 3,45 e para os iniciantes foi 3,37. 0 indicador com nota mínima permaneceu a mesma para ambos, e o indicador de nota máxima para os concluintes passou a ser o de número 6 - Experiência de magistério superior ou experiência profissional do corpo docente, com nota média de 3,83, onde 77,14\% atribuíram conceitos 4 ou 5.

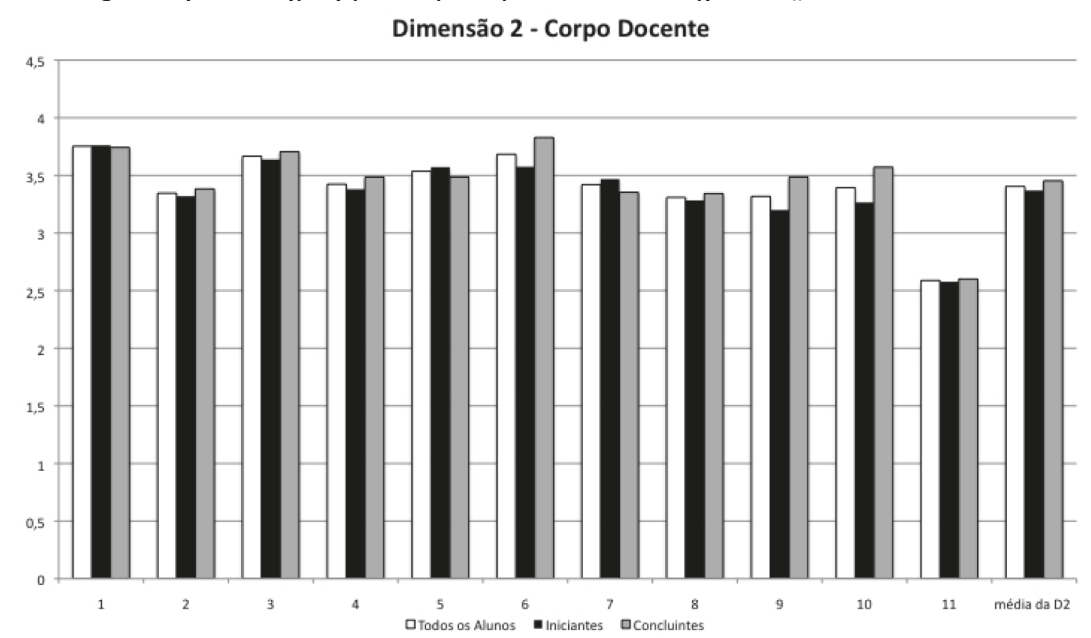

Fonte: As autoras (2010).

\footnotetext{
Dimensão 2 - Corpo Docente

1. Formação do coordenador do curso.

2. Regime de trabalho do coordenador do curso (disponibilidade).

3. Formação e conhecimento do corpo docente.

4. Dedicação do corpo docente ao curso
}

\begin{abstract}
5. Docentes com formação adequada às $\quad$ 8. Adequação da quantidade de técnicounidades de ensino e atividades desenvolvidas administrativos às necessidades do curso. no curso. $\quad 9$. Número de vagas ofertadas nas disciplinas 6. Experiência de magistério superior ou experiência profissional do corpo docente. 7. Adequação da formação e experiência profissional do corpo técnico-administrativo. científica) e número de produção por docente.
\end{abstract}

Os testes de médias dos conceitos atribuídos aos indicadores da dimensão 2 são apresentados na tabela 3 . Para os indicadores $1 ; 3 ; 6$; e 11 , o teste de Levene não encontrou evidências de igualdade de variâncias para os conceitos dados pelos grupos de alunos ingressantes e concluintes, sendo conduzido o teste de médias não assumindo igualdade de variâncias para esses quesitos. Para os outros indicadores foram conduzidos teste de médias assumindo igualdade de variâncias. Os resultados dos testes não rejeitaram a hipótese nula (sig. $>0,05)$, indicando que, apesar de aparentemente os alunos concluintes terem avaliado melhor, na prática os dois grupos de alunos têm percepção similar em relação ao corpo docente do curso de Ciências Contábeis. 
Tabela 3 - Resultados do teste de médias dos indicadores da dimensão 2.

\begin{tabular}{l|c|c|c|c|c}
\hline Indicadores & \multicolumn{2}{|c|}{ Resultado teste de Levene } & \multicolumn{3}{c}{ Teste t para igualdade das médias } \\
\hline & Estatística $\mathrm{F}$ & Significância & Estatística $\mathrm{t}$ & Significância & Diferença das médias \\
\hline 1 & 5,581 & 0,021 & $0,087^{* *}$ & 0,931 & 0,018 \\
\hline 2 & 0,044 & 0,834 & $-0,290^{*}$ & 0,773 & $-0,063$ \\
\hline 3 & 3,336 & 0,072 & $-0,329^{* *}$ & 0,743 & $-0,068$ \\
\hline 5 & 0,243 & 0,623 & $-0,553^{*}$ & 0,582 & $-0,106$ \\
\hline 6 & 2,397 & 0,125 & $0,483^{*}$ & 0,630 & 0,086 \\
\hline 7 & 7,728 & 0,007 & $-1,356^{* *}$ & 0,179 & $-0,254$ \\
\hline 9 & 1,568 & 0,214 & $0,538^{*}$ & 0,592 & 0,115 \\
\hline 10 & 0,002 & 0,968 & $-0,287^{*}$ & 0,775 & $-0,060$ \\
\hline 11 & 2,003 & 0,161 & $-1,213^{*}$ & 0,228 & $-0,286$ \\
\hline \hline
\end{tabular}

Fonte: As autoras (2010).

Legenda dos indicadores: (1) Formação do coordenador do curso; (2) Regime de trabalho do coordenador do curso (disponibilidade); (3) Formação e conhecimento do corpo docente; (4) Dedicação do corpo docente ao curso; (5) Docentes com formação adequada às unidades de ensino e atividades desenvolvidas no curso; (6) Experiência de magistério superior ou experiência profissional do corpo docente; (7) Adequação da formação e experiência profissional do corpo técnicoadministrativo; (8) Adequação da quantidade de técnico-administrativos às necessidades do curso; (9) Número de vagas ofertadas nas disciplinas; (10) Alunos por turma em disciplina teórica; (11) Desenvolvimento de pesquisa, com participação de estudantes (iniciação científica) e número de produção por docente. $\left({ }^{*}\right)$ Assumindo variâncias iguais; $\left(^{* *}\right)$ Não assumindo variâncias iguais.

A Dimensão 3 - Instalações Físicas (D3) ficou com a menor nota média das três dimensões, 2,63, cujo desvio padrão da amostra D3 é de 1,09, e o desvio-padrão dos indicadores é de 0,18. Dentre seus indicadores, o que obteve maior nota foi o de número 4-Processo de registros acadêmicos informatizados e implantados, com garantia de atualização, confiabilidade e eficiência, e o acesso ao discente, com 2,94; e o que obteve menor nota foi o indicador de número 8-Laboratórios especializados destinados às aulas práticas, que atendam às demandas do curso, com 2,37. Nota-se que $52 \%$ dos alunos deram conceitos 1 ou 2 para os indicadores dessa dimensão.

Ainda na Dimensão 3 - Instalações Físicas (D3), a nota média dos iniciantes e dos concluintes ficaram muito próximas, 2,72 e 2,51, respectivamente. 0 indicador de nota máxima da D3 permaneceu o mesmo para ambos. Já o indicador de nota mínima, para os concluintes, passou a ser o de número 7 - Assinaturas de periódicos especializados, indexados e correntes, atualizados em sua maioria, abrangendo as principais áreas temáticas do curso, disponivel na biblioteca, com nota 2,29, onde $62,86 \%$ dos estudantes atribuiram conceitos 1 ou 2, indicando que não há ou é insuficiente. 
Figura 3: Conceitos atribuídos pelos alunos para a dimensão 3.

Dimensão 3 - Instalações Físicas

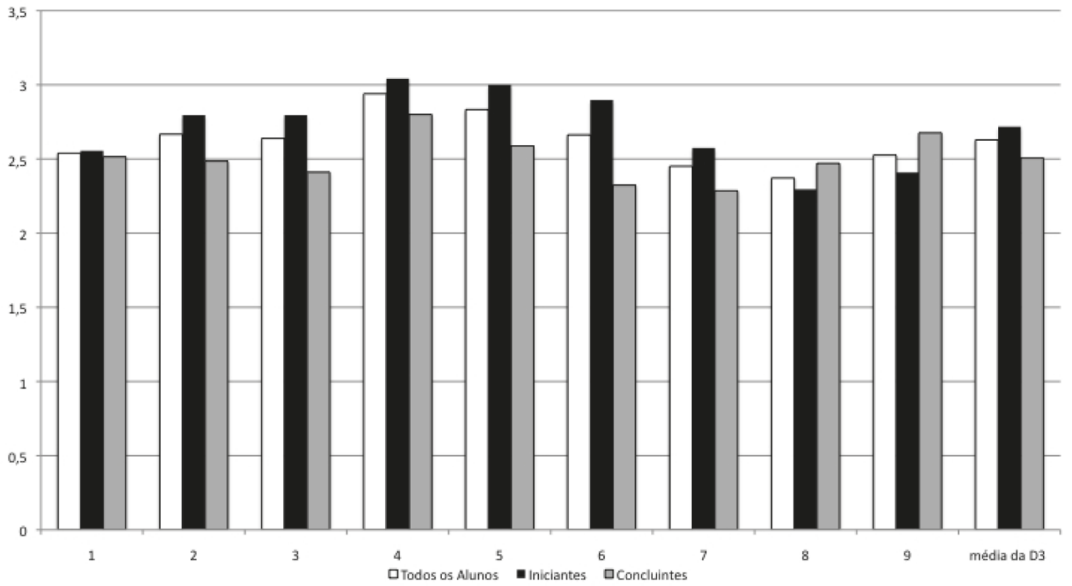

Fonte: As autoras (2010).

Dimensão 3 - Instalações Físicas

1. Sala de professores e sala de reuniões atendem aos requisitos de dimensão, acústica, limpeza, ventilação, conservação e comodidade necessária à atividade desenvolvida.

2. Salas de aula equipadas segundo a necessidade e atendem aos requisitos do indicador 1

3. Disponibilidade de laboratório de informática com acesso a internet.
4. Processo de registros acadêmicos informatizado e implantado, com garantia de atualização, confiabilidade e eficiência, e o acesso ao discente. Trítos indicados na bibliografia básica dos 8. Laboratórios especializados destinados às programas das disciplinas do curso disponível aulas práticas, que atendam às demandas do na biblioteca.

6. Acervo atende às indicações bibliográficas 9. Espaços, equipamentos e serviços complementares, referidas nos programas das destinados aos laboratórios especializados disciplinas, disponivel na biblioteca.
7. Assinaturas de periódicos especializados, indexados e correntes, atualizados em sua maioria, abrangendo as principais áreas atendem às atividades ali desenvolvidas. temáticas do curso, disponivel na biblioteca. curso.

Na Tabela 4, são apresentados os testes de médias com os indicadores da dimensão 3 (instalações físicas). Apenas para os indicadores 2; 3; e 7 foi utilizado o teste de médias não assumindo igualdade de variâncias. Os resultados mostram que os dois grupos de alunos atribuíram menções diferentes para o quesito acervo atende às indicações bibliográficas complementares, referidas nos programas das disciplinas, disponível na biblioteca (indicador 6), como pode ser observado pela significância do teste $<0,01$. Neste caso, os alunos ingressantes avaliaram melhor o acervo da biblioteca, verificado pela diferença positiva das médias $(0,574)$.

A maioria das disciplinas obrigatórias dos primeiros semestres do Curso de Ciências Contábeis faz parte da grade curricular de muitos cursos oferecidos pela Universidade de Brasília e, assim, as indicações bibliográficas referidas nos programas dessas disciplinas são encontradas na biblioteca com mais facilidade.

Por outro lado, nos últimos semestres, as disciplinas são mais especificas do curso e os concluintes têm uma dificuldade maior de encontrar na biblioteca as bibliografias indicadas nos seus referidos programas. Assim, entende-se a diferença significativa dos conceitos atribuídos pelos alunos ingressantes e concluintes. 
Para os demais indicadores, os testes de médias não rejeitaram a hipótese nula (sig. $>0,05$ ), denotando que os alunos ingressantes e concluintes têm praticamente a mesma percepção em relação a maioria dos itens da dimensão 3.

Tabela 4 - Resultados do teste de médias dos indicadores da dimensão 3.

\begin{tabular}{l|c|c|c|c|c}
\hline Indicadores & \multicolumn{2}{|c|}{ Resultado teste de Levene } & \multicolumn{3}{|c}{ Teste t para igualdade das médias } \\
\hline & Estatística F & Significância & Estatística t & Significância & Diferença das médias \\
\hline 1 & 0,878 & 0,352 & $0,159^{*}$ & 0,874 & 0,040 \\
\hline 2 & 8,050 & 0,006 & $1,357^{* *}$ & 0,178 & 0,310 \\
\hline 3 & 3,243 & 0,075 & $1,512^{* *}$ & 0,134 & 0,384 \\
\hline 5 & 0,190 & 0,664 & $0,910^{*}$ & 0,365 & 0,242 \\
\hline 6 & 1,594 & 0,210 & $1,873^{*}$ & 0,065 & 0,412 \\
\hline 7 & 1,289 & 0,260 & $2,853^{*}$ & 0,006 & 0,574 \\
\hline 8 & 3,921 & 0,051 & $1,386^{* *}$ & 0,170 & 0,289 \\
\hline 9 & 2,136 & 0,148 & $-0,684^{*}$ & 0,496 & $-0,175$ \\
\hline
\end{tabular}

Fonte: As autoras (2010).

Legenda do indicadores: (1) Sala de professores e sala de reuniões atendem aos requisitos de dimensão, acústica, limpeza, ventilação, conservação e comodidade necessária à atividade desenvolvida; (2) Salas de aula equipadas segundo a necessidade e atendem aos requisitos do indicador 1; (3) Disponibilidade de laboratório de informática com acesso a internet; (4) Processo de registros acadêmicos informatizado e implantado, com garantia de atualização, confiabilidade e eficiência, e o acesso ao discente; (5) Títulos indicados na bibliografia básica dos programas das disciplinas do curso disponivel na biblioteca; (6) Acervo atende às indicações bibliográficas complementares, referidas nos programas das disciplinas, disponivel na biblioteca; (7) Assinaturas de periódicos especializados, indexados e correntes, atualizados em sua maioria, abrangendo as principais áreas temáticas do curso, disponível na biblioteca; (8) Laboratórios especializados destinados às aulas práticas, que atendam às demandas do curso; (9) Espaços, equipamentos e serviços destinados aos laboratórios especializados atendem às atividades ali desenvolvidas. (*) Assumindo variâncias iguais; $\left.{ }^{* *}\right)$ Não assumindo variâncias iguais.

A Tabela 5 apresenta os conceitos atribuídos as três dimensões pelos iniciantes, concluintes e média geral. Enquanto a Média Ponderada Final dada pelos iniciantes ficou em 3,2, a Média Ponderada Final atribuida pelos alunos concluintes chegou a 2,99. Embora tenha ocorrido uma ligeira diferença entre as opiniões de grupos de alunos, no conceito geral, o curso de Ciências Contábeis ficou igual a 3, representando, um nivel de satisfação do aluno igual a suficiente. Logo, a UnB necessita realizar uma reflexão sobre o projeto político e pedagógico do curso, bem como sobre a oferta de disciplinas, de serviços especializados e das condições estruturais da instituição para que ocorram correções nos itens elencados pelos alunos. 
Tabela 5 - Conceitos das dimensões.

\begin{tabular}{|c|c|c|c|c|c|c|c|}
\hline & \multirow{2}{*}{ Dimensões } & \multicolumn{3}{|c|}{ Conceitos das Dimensões } & \multicolumn{3}{|c|}{ Conceitos Finais } \\
\hline & & MPF & Moda & Conceito & MPF & Moda & Conceito \\
\hline \multirow{3}{*}{ Geral } & D1 & 3,10 & 3 & 3 & \multirow{3}{*}{3,11} & \multirow{3}{*}{3} & \multirow{3}{*}{3} \\
\hline & D2 & 3,40 & 3 & 3 & & & \\
\hline & D3 & 2,63 & 2 & 2 & & & \\
\hline \multirow{3}{*}{ Iniciantes } & D1 & 3,27 & 3 & 3 & \multirow{3}{*}{3,2} & \multirow{3}{*}{3} & \multirow{3}{*}{3} \\
\hline & D2 & 3,37 & 3 & 3 & & & \\
\hline & D3 & 2,72 & 2 & 3 & & & \\
\hline \multirow{3}{*}{ Concluintes } & D1 & 2,89 & 3 & 3 & \multirow{3}{*}{2,99} & \multirow{3}{*}{3} & \multirow{3}{*}{3} \\
\hline & D2 & 3,45 & 4 & 4 & & & \\
\hline & D3 & 2,51 & 2 & 2 & & & \\
\hline
\end{tabular}

Fonte: As autoras (2010).

Ao analisar o conceito de cada dimensão, a Dimensão 1 - Organização DidáticoPedagógica permaneceu com conceito 3, seja quando avaliada por todos os alunos, seja apenas pelos iniciantes ou pelos concluintes.

A Dimensão 2 - Corpo Docente obteve conceito 3 quando avaliada por todos os alunos da amostra ou apenas pelos iniciantes. Porém, quando avaliado pelos alunos concluintes, esta dimensão apresentou conceito 4.

A Dimensão 3 - Instalações Físicas permaneceu com conceito 3 apenas quando avaliada pelos alunos iniciantes. Quando avaliada pelos alunos concluintes, ou por todos os alunos da amostra, o conceito desta dimensão caiu para 2.

Conclui-se que a Média Ponderada Final da avaliação do Curso de Ciências Contábeis ficou com conceito final 3, quando avaliado por todos os alunos da amostra ou quando avaliado separadamente por iniciantes e concluintes.

\section{Considerações finais}

Realizou-se uma pesquisa com estudantes iniciantes e concluintes do Curso de Ciências Contábeis da UnB com o objetivo principal de verificar quais são os pontos fortes e fracos da organização didático-pedagógica, do corpo docente e das instalações físicas desse curso. Atingiu-se o objetivo quando, observando os resultados, alguns indicadores se destacaram por receber conceitos abaixo e acima da média, com quantidade significativa de alunos atribuindo a mesma nota.

Apresentou-se como ponto forte os indicadores referentes à formação, ao conhecimento e à experiência acadêmica e profissional dos coordenadores do curso e do corpo docente, aos quais mais de $62 \%$ dos alunos atribuíram conceito 4 ou 5 . 
Por outro lado, o indicador referente aos programas de atendimento extraclasse, de apoio psicopedagógico e às atividades de nivelamento apresentou-se como ponto fraco, bem como os indicadores referentes ao estágio supervisionado, às assinaturas de periódicos e aos laboratórios destinados às aulas práticas, aos quais mais de 54\% dos alunos atribuíram conceitos 1 ou 2.

Ao analisar em conjunto os conceitos atribuídos pelos estudantes iniciantes e concluintes, atingiu-se o objetivo específico ao comparar a diferença entre os conceitos dados. De maneira geral, os alunos ingressantes e concluintes da instituição atribuíram notas similares aos indicadores, embora tenham sido verificadas algumas diferenças de avaliação entre estes alunos nos quesitos relacionados, em sua maioria, à dimensão organização didático-pedagógica. A diferença de percepções dessa dimensão pode estar relacionada com a posição dos alunos no fluxo curricular, uma vez que os alunos ingressantes ainda não tiveram contato com as atividades do final do curso (estágio supervisionado e TCC, por exemplo), logo eles não teriam subsídios suficientes para avaliar esses itens, mostrando uma expectativa positiva do que eles esperam dessas atividades.

Ante o questionamento apresentado, de como o Curso de Ciências Contábeis da UnB seria avaliado por seus alunos numa avaliação in loco, para o qual se utilizou um instrumento semelhante ao aplicado pelo Inep, "Reconhecimento de Curso de Graduação de Bacharelado e Licenciatura", chegou-se ao seguinte resultado: Os alunos avaliaram o Curso de Ciências Contábeis da UnB atribuindo-Ihe conceito 3, o qual indica que as dimensões organização didático-pedagógica, corpo docente e instalações físicas se apresentam de forma suficiente.

Ao concluir o presente trabalho, verificou-se a contribuição que este pode dar à coordenação do Curso de Ciências Contábeis da UnB no planejamento de melhoria às condições de estudo oferecidas aos alunos.

0 questionário aplicado foi um instrumento onde os estudantes puderam expressar o grau de satisfação diante de diversos pontos não abordados por outros instrumentos de avaliação aplicados nesta Instituição de Ensino. Fica, portanto, a sugestão de se aplicar este questionário avaliativo aos demais cursos de graduação da UnB, ou ainda levá-lo às outras IES.

Ressalve-se que a pesquisa, realizada com os estudantes selecionados para fazer a prova do Enade 2009, merece ser aprofundada, o que pode ser feito estendendo a aplicação do questionário a todos os alunos do Curso de Ciências Contábeis. É necessário, também, fazer uma apresentação dos coordenadores do curso e do corpo técnicoadministrativo do departamento, bem como mostrar os laboratórios e salas dos professores aos alunos iniciantes. Desta forma, constitui-se uma perspectiva de continuidade com a qual se pretende alcançar uma melhor representação da realidade. 


\section{Referências}

ALIGLERI, L. A.; MACRINI, D. A teoria das restrições como alternativa de gestão para Instituições de Ensino Superior Privada. In: CONGRESO ARGENTINO DE PROFESORES UNIVERSITARIOS DE COSTOS TANDIL, 27., 2004, Tandil. Anais eletrônicos... Provincia del Chaco, Argentina, 2004. Disponivel em: $<$ http:// eco.unne.edu.ar/contabilidad/costos/mercosur/trabajo04_mercosur.pdf $>$. Acesso em: nov. de 2011.

BRASIL. Lei no 10.861, de 14 de abril de 2004. Institui o Sistema Nacional de Avaliação da Educação Superior - SINAES. Diário Oficial [da] República Federativa do Brasil, Brasilia, DF, 15 abr. 2004. Seção, p. 3. Disponivel em: <http://www.planalto.gov.br/ccivil_03/_ato2004-2006/2004/Lei/L10.861.htm>. Acesso em: 27 fev. 2012.

. Portaria Normativa $n^{\circ} 1$, de 29 de janeiro de 2009. Determina as áreas e os cursos superiores de tecnologia que serão avaliados pelo Exame Nacional de Desempenho dos Estudantes (ENADE) no ano de 2009 e dá outras providências. Diário Oficial [da] República Federativa do Brasil, Brasília, DF, 30 jan. 2009a. Seção 1, p. 37-37. Disponivel em: <http://www.anaceu.org.br/conteudo/ legislacao/portarias/2009\%20-\%20Portaria\%20Normativa\%201\%20\%2029\%20janeiro.pdf>. Acesso em: 27 fev. 2012.

. Ministério da Educação. Portaria n ${ }^{\circ}$ 2, de 5 de janeiro de 2009. Aprova, em extrato, o instrumento de avaliação para reconhecimento de cursos de graduação - Bacharelados e Licenciaturas do Sistema Nacional de Avaliação da Educação Superior - SINAES. Diário Oficial [da] República Federativa do Brasil, Brasília, DF, 6 jan. 2009b. Seção 1, p. 8. Disponível em: <http:// download.inep.gov.br/download/superior/condicoesdeensino/ Extrato_reconhecimento_direito.pdf>. Acesso em: 27 fev. 2012.

BUENO, F. S. Minidicionário da língua portuguesa. Rev. e atual. por Helena Bonito C. Pereira, Rena Signer. São Paulo: FTD: LISA, 1996.

DIAS SOBRINHO, J. Avaliação: políticas educacionais e reformas da educação superior. São Paulo: Cortez, 2003.

DIAS SOBRINHO, J. Avaliação da educação superior. Petrópolis: Vozes, 2000.

FREIRE, F. S.; CRISÓSTOMO, V. L.; CASTRO, J. E. G. Análise do desempenho acadêmico e indicadores de gestão das IFES. Produção on Line, Florianópolis, SC, 2007. Edição Especial. 
FREUND, J. E.; SIMON, G. A. Estatística aplicada: economia, administração e contabilidade. Trad. Alfredo Alves de Farias. 9. ed. Porto Alegre: Bookman, 2000.

GOLDRATT, E. M. A meta. São Paulo: Claudiney Fullmann, 1993.

INEP. Sinaes: Sistema Nacional de Avaliação da Educação Superior: avaliação externa das instituições de educação superior: diretrizes e instrumento. Brasilia, DF, 2006a.

Sinaes: Sistema Nacional de Avaliação da Educação Superior: da concepção à regulamentação. 2. ed. ampl. Brasilia, DF, 2004. Disponivel em: <http:// www.publicacoes.inep.gov.br/arquivos/\{B 4E0C6B4-314B-4F70-9671E33A4BA67C42\}_Sinaes_da_concepção_à_regulamentação.pdf> Acesso em: nov. de 2009.

. Sistema Nacional de Avaliação da Educação Superior: Exame Nacional de Desempenho de Estudantes 2006: relatório de curso: Curso de Ciências Contábeis da UnB. Brasilia, DF, 2006b. Disponivel em: <http:// enade2006.inep.gov.br/pdf/2200025300108.pdf>. Acesso em: nov. de 2009.

MARINHO, A.; FAÇANHA, L. Dois estudos sobre a distribuição de verbas públicas para as instituições federais de ensino superior. Brasília: IPEA, 1999.

REAL, G. C. M. Impactos da avaliação na educação superior. Campo Grande: UFGD, 2008.

SCHLICKMANN, R.; MELO, P. A.; ALPERSTEDT, G. D. Enfoques da teoria institucional nos modelos de avaliação institucional brasileiros. Avaliação, Campinas, SP, v.13, n.1, p. 153-168, 2008.

SCHMITZ, J. L. Do currículo aos exames nacionais: uma análise da aderência do currículo do curso de ciências contábeis da UFSC às diretrizes curriculares nacionais, ao ENADE e ao exame de suficiência do CFC. 2008. 258 F. Dissertação (Mestrado)-Programa de Pós-Graduação em Contabilidade, Universidade Federal de Santa Catarina, Florianópolis, 2008.

SCHWARTZMAN, S. O contexto institucional e político da avaliação do Ensino Superior. São Paulo: NUPES/USP, 1990.

SOUZA, E. S. Enade 2006: determinantes do desempenho dos cursos de ciências contábeis. 2008. 96 f. Dissertação (Mestrado)-Programa Multinstitucional e Inter-Regional de Pós-Graduação em Ciências Contábeis, da Universidade de Brasilia, Universidade Federal da Paraiba, Universidade Federal do Rio Grande do Norte, Brasilia, DF, 2008. 
SOUZA, L. M. et al. Aplicação da teoria das restrições na gestão do fluxo de disciplinas do curso de Ciências Contábeis da Universidade de Brasília. In: CONGRESSO BRASILEIRO DE GESTÃO ESTRATÉGICA DE CUSTOS, 16., 2009, Fortaleza. Anais... Fortaleza: UFC, 2009. 1 CD-ROM.

STEIN, M. G. D. F. Avaliação institucional: um estudo realizado em três instituições mineiras de ensino superior. 2002. Dissertação (Mestrado)Universidade Metodista de Piracicaba, São Paulo, 2001.

WOLYNEC, E. 0 uso de indicadores de desempenho para a avaliação institucional. In: DURHAM, E. R.; SCHWARTZMAN, S.(Org.). Avaliação do ensino superior. São Paulo: Ed. da USP, 1992.

Recebido em: 17/01/2011

Aceito para publicação em: 14/12/2011 